\title{
International Transmission of Information: A Study of the Relationship Between the U.S. and Greek Stock Markets*
}

\author{
Nikitas Niarchos \\ University of Athens, Greece \\ Yiuman Tse \\ State University of New York at Binghamton, U.S.A. \\ Chunchi Wu \\ Syracuse University, U.S.A. \\ Allan Young \\ Syracuse University, U.S.A.
}

This article investigates the international information transmission between the U.S. and Greek stock markets using daily data from the Athens Stock Exchange (ASE) and the S\&P 500 Index returns. It employs a bivariate exponential GARCH-t (EGARCH-t) that allows for both mean and variance spillovers between the two markets. It also performs cointegration tests on the long-run relation between these two markets and explores the possible common volatility feature in the spirit of Engle and Kozicki (1993). The results show no spillovers between these two markets for the conditional mean and variance. Also, the cointegration test shows that these two markets are not driven by a common trend. It appears that the U.S. and Greek stock markets are not related to each other, either in the short-run or in the long-run. Contrary to previous studies of the world's large financial markets, the evidence here shows that the U.S. market does not have a strong influence on the Greek stock market (JEL G1 G15).

Keywords: cointegration, clustering, EGARCH, heteroskedasticity, spillover

\footnotetext{
${ }^{*}$ Contact address: School of Management, Syracuse University, Syracuse, NY 13244. Tel: 315-443-1040, Fax: 315-443-5457.
}

(Multinational Finance Journal, 1999, vol. 3, no. 1, pp. 19-40)

(C)Multinational Finance Society, a nonprofit corporation. All rights reserved.

DOI: $10.17578 / 3-1-2$ 


\section{Introduction}

The issue of international integration of financial markets has received a great deal of interest from practitioners and academic researchers. This interest was further fueled by the dramatic financial events of October 1997, beginning in Pacific Rim Asia and spreading rapidly, if unevenly, throughout most major international securities markets. This event more than ever brings to light the significance of the relationship of the transmission of information between the emerging and smaller component elements of the world's security market network and the more dominant constituents of this system.

Past studies in the area of international information transmission have focused upon how information flows in one market affect performance in another market. Hamao, Masulis, and $\mathrm{Ng}$ (1990) find significant volatility spillovers from New York to Tokyo and London, and London to Tokyo, but not from Tokyo to other markets, for the pre1987 crash period. In contrast, Koutmos and Booth (1995) and Bae and Karolyi (1994) report that the volatility spillovers between the New York and Tokyo stock markets are significant in both directions for the post-crash period. Significantly, Kahya (1997) finds that when using daily data (as opposed to weekly data) in studying the relationships between the U.S., Japan, and U.K. stock markets, the results show that daily correlations of returns among these major securities markets are biased downward, while daily cross-serial correlations of returns are biased upwards. Using a multiple hypothesis testing method, $\mathrm{Wu}$ and $\mathrm{Su}$ (1998) find that the direction of the lead-lag relation and spillovers between two financial markets may change over time. Lin, Engle, and Ito (1994) find little evidence of volatility spillovers from New York to Tokyo stock markets after adjusting for the stale quotes in the market opening. Further, to overcome the problems of nonsynchronous trading and market segmentation, Tse (1998) examines Euroyen and Eurodollar futures data and finds that there is no volatility spillover between the U.S. and Japanese markets. In terms of the relationship between some less active securities markets, Booth, Martikainen, and Tse (1997) study the price volatility spillovers among the Danish, Norwegian, Swedish, and Finnish stock markets. They find that volatility transmission is asymmetric, spillovers being more pronounced for bad news than good. They also show that while significant price and volatility spillovers exist among these stock markets, they are few in number.

Although empirical regularities of the nature of information 
transmission are well documented for large international financial centers (and some findings of the relationship among less active markets have been generated), less is known about the information interaction between emerging and developed securities markets. Emerging markets are typically much smaller, less liquid, and more volatile than wellknown world financial markets. ${ }^{1}$ There is also some evidence that emerging markets may be less informationally efficient. This could be due to several factors such as poor-quality (low precision) information, high trading costs, and/or less competition due to international investment barriers. Further, the industrial organization found in emerging economies is often quite different from that in developed economies. All of these conditions and others may contribute to a lower correlation between the securities markets of developed and emerging countries.

This article investigates international information transmission between the U.S. and Greek stock markets, using daily data from the Athens Stock Exchange (ASE) and the S\&P 500 index returns for the period January 1993 to September 1997. Recent world events have brought increased attention to the Balkan region and heightened concern with the ability of one of the largest securities markets in the area to function effectively during times of economic and political crisis and change. ${ }^{2}$ The main objective of this article is to study how much of the volatility in one market can be explained by volatility innovations in the other market and how fast these movements transfer between these markets. An important issue is whether the Greek market is related to the major international financial centers, such as New York. From an empirical perspective, the Greek market is of particular interest. It is a prototype of emerging markets, some of which performed particularly well in a number of recent years, though often with considerable volatility. Further, the ASE has recently undergone a number of dramatic changes in institutional structure and regulatory policy. It will be interesting to observe how these considerable changes have affected the performance of the ASE and its relation to U.S. security trading.

1. See Domowitz, Glen, and Madhavan (1998).

2. See, for example, Hugh Pope, "Greece Is Wearing European Mantle Well: Robust Stock Market Suggests EU Largess Isn't in Vain," The Wall Street Journal, September 10, 1997, p. A18, Nicholas Bey, "Greek Government to Present '98 Budget As Speculation Rises over Devaluation," The Wall Street Journal, November 11, 1997, p. A14, and Deborah Ball, "In Greece, Serbia War May Roil Markets,"The Wall Street Journal, April 7, 1999, p. A17. 
There are only a few studies of the Greek stock market. Papaioannou and Philippatos (1982) examined the impact of nonsynchronous trading on the beta estimates of the market model using Greek stock market returns. Niarchos and Georgakopoulos (1986) found that the Greek stock prices respond very slowly to new information and conclude that the Greek market is not efficient. In an article addressing the dependence between the Greek and U.S. stock markets, Theodossiou, Koutmos, and Negakis (1993) used data from the period July 1981 to August 1990 to test for dependencies in the first moments of the joint distribution of stock market returns between the two countries. They also investigated the extent to which the second moments of returns (volatilities) were time-dependent and linked. They further looked at the magnitude and structure of the correlation of returns over time. Their results indicated that for the time period they studied, current returns in the Greek market were influenced by past returns in the U.S. market. However, it was found that volatility in the Greek market was not influenced by innovations in the U.S. market.

This article differs from previous studies in several aspects. First, it employs a bivariate exponential GARCH-t (EGARCH-t) that allows for both mean and variance spillovers between the two markets. This model is well known for its ability to capture the information transmission between markets. It tests for the existence of two types of volatility processes: heat waves and meteor showers. The heat wave hypothesis postulates that volatility has only country-specific autocorrelation, whereas the meteor shower hypothesis posits that volatility can spill over from one market to another. The model can also be used to detect the potential asymmetry of stock market response to good and bad news. Previous studies (e.g., Bae and Karolyi, 1994; Koutmos and Booth, 1995; Booth, Martikainen, and Tse, 1997) have found that the volatility transmission between international markets is often asymmetric. An EGARCH model is especially suitable for investigating the asymmetric impact of good and bad news on the volatility transmission between markets. Second, it conducts cointegration tests on the long-run relation between these two markets and explores the possible common volatility feature in the spirit of Engle and Kozicki (1993). This contrasts with previous studies that focused mainly on the short-run dynamic relationship between markets. Finally, this study uses more current data to capture the effects of recent important structural and policy changes in the Greek stock market. In contrast to the findings of Theodossiou et al. (1993), this study finds 
that neither the mean nor the volatility of the Greek market returns are influenced by past U.S. market returns and return innovations over a more recent sample period.

A study of the relationship between the U.S. and Greek stock markets can provide important evidence as to how strongly international markets are related. It has long been argued that today's international financial markets are becoming increasingly more related due to advanced information technology and improved processing of information that significantly lowers the costs of international financial transactions. At the same time there is a worldwide trend towards international capital market liberalization that gradually removes transaction barriers and enhances information flows between nations. However, differences in economic structures, geographic characteristics, political systems, and financial regulation remain quite significant between countries, particularly for those nations in different regions. Although Greece has a substantial trade relationship with the U.S., the social and economic structures are rather different between the U.S. and Greece, possibly causing a disparity between these two markets. Investigation of the relationship between them should provide useful information for understanding the extent of the international market co-movement in recent years.

The remainder of this article is organized as follows. Section I describes the unique institutional features of the ASE and their effects on asset price dynamics. Section II presents the empirical methodology to examine the mechanisms of information transmission between the two markets. Section III discusses the data and empirical results. Finally, the last section summarizes the major findings of the article.

\section{Institutional Features of the $\mathrm{ASE}^{3}$}

The ASE for a number of years has been characterized as an emerging market and has attracted international interest. This exchange was established in 1887 and is the only stock exchange in Greece. ${ }^{4}$ During

3. Since the institutional features of U.S. secondary security trading are rather well known, the present section focuses primarily upon the ASE and refers to U.S markets only to point out the basic similarities and differences.

4. This is as opposed to U.S. secondary security trading where four different markets are operative. There is exchange trading which is dominated by the NYSE. Over-the-counter 
the past 15 years it has entered a period of new structural reforms and development. As a result, the market has become potentially more efficient and competitive. Though the Greek stock market is rather small by international standards, it has grown considerably since 1987 and has become more international due to the liberalization of capital movements. Hence, it is able to compete favorably with other, more developed exchanges, especially after the introduction of electronic trading in 1992. Since the end of 1986, the Greek stock market has been under continuous structural transformation. The number of listed companies increased significantly, market liquidity improved, and structural and legislative reforms provided for a modern and adequate regulatory framework. The ASE is in the process of continuous modernization and alignment with advanced international stock markets.

The ASE's "big bang" was attempted with Law 1806, which came into force in 1988 and replaced the previous out-of-date legislation of 1928. The new law brought major changes to the market. A parallel market for smaller companies was developed, a Central Security Depository was established in 1990, and the establishment of brokerage companies was permitted for the first time. In July 1995 the stock market authorities enacted a new law, the purpose of which was to further improve market efficiency and transparency. This law imposes stricter requirements on companies applying for admission to the ASE. However, this law also foresees that, in new admissions, the underwriters bear responsibility for the accuracy of the data and the information published by the issuer in the prospectus prior to an initial public offering. Members of the ASE are brokerage companies with a fixed amount of capital required by law. To secure against default and settlement risks, members have to contribute to a dedicated fund, "the ASE Members Guarantee Fund". The size of each member's contribution as well as the management of the fund's portfolio are determined by law. Listed stocks can be in bearer or registered form. However, shares from the banking, insurance, leasing, real estate, and health care sectors must, by law, be registered.

The ASE contains two market segments, the "main" and the "parallel market". The main market primarily includes larger firms with higher equity capital and operating profits. In contrast, stocks traded in

trading is represented primarily by the NASDAQ system. Additionally, the third market constitutes over-the-counter trading in exchange-listed stocks. Finally, direct principal-toprincipal, over-the-counter security trading in exchange-listed stocks is generally referred to as the fourth market. 
the parallel market typically have lower equity capital, a smaller scale of operation, and lower profits. A computerized automated electronic trading system, inaugurated on August 17, 1992, gradually replaced the previous open outcry system. Since the beginning of 1993, all listed shares are traded over the new trading system. The system is continuous and order-driven in that it matches orders from opposite sides of the market. ${ }^{5}$ Trading is carried out on the trading floor located in the ASE building. The electronic trading system introduced by the ASE is similar to the Continuous Automatic Trading System (CATS) on the Toronto Stock Exchange and has made the market more transparent. As a result, the volume of trading has increased dramatically and investors know immediately the price of order execution and the number of shares bought or sold at each price.

The trading session lasts from 10:45 a.m. to 1:30 p.m., which does not overlap U.S. market trading. ${ }^{6}$ A 30 -minute period preceding the commencement of trading, the pre-opening period, is set to allow brokers to enter orders into the system. Opening prices are calculated by the system during the pre-opening period and are the prices that maximize turnover for each security. Off-floor trading is not permitted. ${ }^{7}$ To avoid dramatic price movements, the ASE has introduced limits in the permitted daily price changes. ${ }^{8}$ Most shares are allowed to swing in a range of plus or minus eight percent from the last trading day's closing price. For illiquid shares, this span is plus/minus four percent. New issues that are admitted to ASE trading can swing +/- $99 \%$ daily for the first three days of trading. This large daily movement allows new issues to discover their equilibrium price at the outset. Block trades can be carried out within a span of five percent above or below the day's market range if the value is up to GRD 400 million, and ten percent if the value exceeds GRD 400 million.

Like the NYSE, market and limit orders are allowed. ${ }^{9}$ An order to

5. The NYSE is a continuous auction market and is also order-driven. Recent NASDAQ rule changes have also moved this system more towards an order-driven status.

6. Athens is generally seven hours in advance of U.S. Eastern Standard Time.

7. This is very different from the U.S. secondary security markets, where considerable off-floor trading in exchange-listed stocks is conducted.

8. The NYSE circuit breakers are the closest U.S. analogy.

9. The NYSE also normally allows stop orders on market plus ticks and zero-plus ticks and other less popular order types. 
buy or sell at the opening price should be executed at the first transaction price recorded on the quotation board for that particular stock. The broker can execute such an order at any time during the trading session, but only at the first transaction price that occurs. An order to buy or sell at the closing price should be executed at the last transaction price recorded on the board. Hence, the broker seeks to execute such an order at the last moment of the trading session.

Foreign institutional and private investors are able to invest and trade in Greek securities regardless of the percentage of the company's shares held or intended to be held. Foreign investors must have a custodial account with a Greek bank either directly or through their global custodian. Nominee registration is not permitted under current legislation in Greece. A minimum holding period for investment in securities does not exist. Repatriation of the initial capital plus any capital gains and dividends or interest income resulting from foreign investments is possible without any restrictions whatsoever. There is no capital gains tax. Corporate profits, both retained and paid out, are subject to a flat rate of $35 \%$ withheld at the source. Non-residents can reclaim the tax withheld and be taxed according to bilateral tax concessions between Greece and the investor's registration country. There are no currency restrictions for non-residents. Banks involved in such transactions must only check the authenticity of the transactions. The certification that the funds for buying the securities have been properly imported is required when the securities are sold and the proceeds exported.

In summary, the structure and organization of the Greek stock market is in many ways different from the U.S. market. These distinct features may affect the temporal behavior of stock prices and the relation with the U.S. market. As indicated, a number of recent reforms have been introduced to increase the liquidity, efficiency, and transparency of stock trading. Liberalization of the capital market should further improve the possibilities for the Greek stock market to respond more rapidly to new information from the U.S. market.

\section{Methodology}

This section examines information transmission between the U.S. and Greek stock markets using a GARCH type of model developed by Bollerslev (1986). This model allows for the exploration of the 
mechanisms of information transmission in the conditional first and second moments in common stock returns between a well-established large market and an emerging market. The GARCH model is useful for capturing the mild serial correlation and high kurtosis documented for daily stock returns. Moreover, it allows for changing conditional variances or conditional mean returns. It is particularly useful for finding whether there are spillover effects in the mean and variance of stock returns between the two markets. To capture the asymmetric effect of innovations on volatility, it employs Nelson's (1991) exponential GARCH (EGARCH) model of the following form:

$$
\begin{gathered}
\ln \sigma_{t}^{2}=\alpha_{0}+\alpha_{1}\left(\left|z_{t-1}\right|-E\left|z_{t-1}\right|+\theta z_{t-1}\right)+\alpha_{2} \ln \sigma_{t-1}^{2}, \\
z_{t-1}=\varepsilon_{t-1} / \sigma_{t}
\end{gathered}
$$

where $z_{t}$ is the standardized residual of stock returns, and $\theta$ is the parameter measuring the asymmetry of news releases on volatility. As suggested by Nelson (1991), bad news tends to have a larger impact on volatility than good news. If so, the value of $O$ should be negative. Incorporating the asymmetric response parameter allows us to detect if the type of news influences return volatility.

More specifically, this article employs the following bivariate EGARCH(1,1)-MA(1) model to examine the mean and volatility spillover mechanism:

$$
\begin{gathered}
\Delta U S_{t}=a_{1}+b_{1} \varepsilon_{1, t-1}+c_{1} \varepsilon_{2, t-1}+\varepsilon_{1, t}, \\
\Delta G K_{t}=a_{2}+b_{2} \varepsilon_{2, t-1}+c_{2} \varepsilon_{1, t-1}+\varepsilon_{2, t}, \\
\varepsilon_{t} \equiv\left(\begin{array}{c}
\varepsilon_{1, t} \\
\varepsilon_{2, t}
\end{array}\right) \mid \psi_{t-1} \sim \text { Student }-t\left(0, H_{t}, v\right), \\
H_{t} \equiv\left(\begin{array}{cc}
\sigma_{1, t}^{2} & \rho \sigma_{1, t} \sigma_{2, t} \\
\rho \sigma_{1, t} \sigma_{2, t} & \sigma_{2, t}^{2}
\end{array}\right), \\
\ln \left(\sigma_{1, t}^{2}\right)=\omega_{1}+\alpha_{1} G_{1, t-1}+\gamma_{1} G_{2, t-1}+\beta_{1} \ln \left(\sigma_{1, t-1}^{2}\right),
\end{gathered}
$$




$$
\begin{aligned}
& \ln \left(\sigma_{2, t}^{2}\right)=\omega_{2}+\alpha_{2} G_{2, t-1}+\gamma_{2} G_{1, t-1}+\beta_{2} \ln \left(\sigma_{2, t-1}^{2}\right), \\
& G_{i, t}=\left(\left|z_{i, t}\right|-E\left|z_{i, t}\right|+\theta_{i} z_{i, t}\right), z_{i, t}=\varepsilon_{i, t} / \sigma_{i, t}, i=1,2,
\end{aligned}
$$

where $\psi_{t-1}$ is the information set at $t-1, E\left|z_{i, t}\right|=(2 / \pi)^{1 / 2}(\Gamma(\gamma-1) / 2) / \Gamma$ $(\gamma / 2)$, and $v$ is the degree of freedom for the Student- $t$ distribution that addresses the excess kurtosis of the innovations (Bollerslev, 1987). ${ }^{10}$ ) The use of the Student $t$-distribution is appropriate if the estimated degree-of-freedom parameter $v$ is larger than 4 . The subscripts $i=1$ denotes $U S$, and $i=2$ refers to $G K . \Delta U S_{t}$ and $\Delta G K_{t}$ are returns for the U.S. and Greek stock markets, respectively, $\sigma_{i, t}$ and $\sigma_{i, j, t}$ are the conditional variance and covariance, and $\mathrm{H}$ is the conditional matrix of the variance and covariance. ${ }^{11} \epsilon_{i, t}$ is the return innovation and $z_{i, t}$ is the standardized innovation. A preliminary inspection of the data shows significant first-order autocorrelation in the Greek market return. This significant first-order autocorrelation in returns may be induced by nonsynchronous trading (see Miller, Muthuswamy, and Whaley, 1994). To correct for the effect of non-synchronous trading, the model introduces a first-order moving-average term in the mean return equations.

The bivariate return model is estimated by maximizing the following log-likelihood function:

$$
L(\theta)=\sum \ln \left[l_{t}(\Theta)\right]
$$

with $l_{t}=\frac{\Gamma((n+v) / 2)}{\Gamma(v / 2)[\pi(v-2)]^{n / 2}}\left|H_{r}\right|^{-1 / 2}\left[1+\frac{1}{v-2} \varepsilon^{\prime} H_{t}^{-1} \varepsilon_{t}\right]^{-(n+v) / 2}$,

where $n$ is the number of variables and $\Theta$ is the parameter vector of the model.

The conditional mean equation contains both the domestic and foreign lagged-return innovations. The domestic lagged return innovation captures the serial correlation of stock returns, whereas the

10. Susmel and Engle (1994) suggest that using the $t$-distribution generates a more efficient estimation for conditional errors than the normal distribution.

11. Here the model specifies a conditional time-invariant covariance. This assumption is warranted if the cross products of the standardized residuals are not serially correlated. 
foreign market lagged-return innovation describes the mean spillover effect. In the conditional variance equation, the most recent foreign (standardized) volatility surprise is introduced to capture the potential volatility spillover. The coefficients $\gamma_{1}, \gamma_{2}$ thus measure the volatility spillover or meteor shower effect. If either $\gamma_{1}$ or $\gamma_{2}$ were statistically significant, then there would be a meteor shower effect from one market to the other. In contrast, the domestic volatility surprise captures the volatility clustering (ARCH) or heat wave effect. If either $\alpha_{1}$ or $\alpha_{2}$ were significant, it would suggest that the heat wave effect exists for that particular market.

Underlying the GARCH-MA(1) model is the assumption of constant conditional correlation $\rho$ in the variance-covariance matrix. Under this assumption, the cross products of the standardized residuals, $z_{i} z_{j}$, should be serially uncorrelated (see Bollerslev, 1990). A diagnosis is provided to check this assumption with empirical investigation.

The above model can be used to detect the separate volatility and mean spillover effects between the two markets. If there is indeed a spillover effect from the foreign to the domestic market, one should observe significant coefficients associated with these spillover terms. In addition to these short-term dynamic tests, this article conducts the cointegration test to see if these two markets exhibit a long-term equilibrium relation.

\section{Data and Empirical Results}

Daily stock price data are obtained from two markets: the U.S. and Greek stock markets. The S\&P500 Composite Index and the ASE Index (GENIDX) are used to represent these two markets. The sample period starts in January 1993, when electronic trading on the ASE began, and ends in September 1997. ${ }^{12}$ Figure 1 displays the temporal pattern of the two market indexes. Over the sample horizon, the returns of the two markets are roughly the same, but with a very different temporal pattern. It can be visualized that the Greek market is much more volatile than the U.S. market. In general, both markets exhibit a rising trend in stock prices over the sample period.

Table 1 summarizes the statistical characteristics of the two market indexes. The daily average return is slightly higher, but the risk, in

12. Return data are capital appreciation only. 


\section{Place Figure 1 Here}

FIGURE 1.- SP 500 and GENIDX Jan. 1993 - Sep. 1997

TABLE 1. Summary Statistics of Index Returns

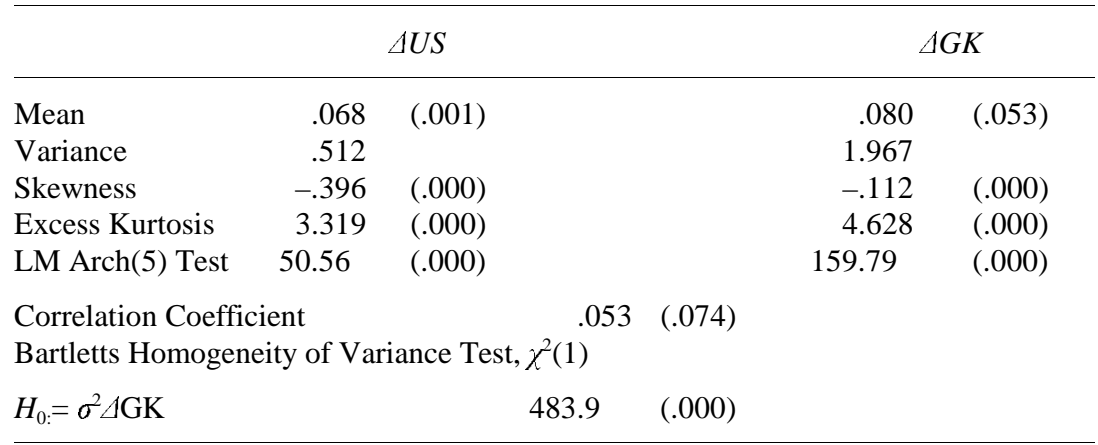

Note: Descriptive statistics are provided for the U.S. and Greek market returns. The sample period is from January 1993 to September 1997. The Lagrange multiplier test suggests a significant $\mathrm{ARCH}$ effect. The correlation coefficient and the variance ratio test statistic are also reported. $P$ values appear in parentheses.

terms of the standard deviation, is much higher for the Greek market. The Bartletts test indicates that the volatility of the Greek market is significantly higher than that of the U.S. market. Both markets show a negative skewness and excess kurtosis (leptokurtic) in return distribution. The kurtosis appears to be higher for the Greek market. 
All moment estimates are statistically different from zero. The excess kurtosis and skewness measures for both series indicate that return distributions of both indices are not normal. Furthermore, the Lagrange multiplier (LM) test shows that both markets exhibit significant ARCH effects. These ARCH effects may explain the fat-tail phenomenon of both index return distributions. The correlation between the two markets is very low, with a correlation coefficient equal to .053, which is barely significant at the ten-percent significance level. As indicated earlier, there is non-overlapping trading between the Greek and U.S. markets; that is, the Greek market closes before the U.S. market opens. To examine the effect of this non-overlapping trading, the correlation between the Greek market return in period $t$ and the U.S. return in period $t-1$ is also estimated. The coefficient of this lagged correlation is even smaller (.026) and statistically insignificant. Thus, the low correlation between these two markets is not due to the non-overlapping trading period.

Table 2 reports the test results for the autocorrelation of returns. According to the Lo and MacKinlay (1988) variance ratio test and Diebold's (1988) Q statistics, the U.S. returns are not significantly autocorrelated. For the Lo and MacKinlay variance ratio, the test statistics are adjusted for serial correlation and heteroskedasticity. ${ }^{13}$ However, returns in the Greek market are significantly autocorrelated, especially for the first three orders of autocorrelation. The first-order autocorrelation is significantly positive, whereas the second-and thirdorder autocorrelations are significantly negative. The magnitude of the first-order autocorrelation is much larger than the remaining autocorrelation coefficients. This high value of the first-order autocorrelation signifies that the Greek market return is predictable in the short run.

Unit root tests are conducted for both indices. The test results are reported in table 3. The augmented Dickey-Fuller (ADF) tests at five lags with and without a time trend show that both series have a unit root. ${ }^{14}$ A similar conclusion is drawn by the Phillips-Perron (1988) tests with the Newey-West (1987) correction for autocovariances. Other lag orders were also tried (up to 10), with a finding that the results were

13. Lo and MacKinlay (1988) propose two test statistics, $Z$ and $Z$. The first one is not corrected for serial correlation and heteroskedasticity, but the second one is. This article employs $Z^{*}$ in its empirical tests

14. See Dickey and Fuller $(1979,1981)$. 
TABLE 2. Tests for Autocorrelation

\begin{tabular}{|c|c|c|c|c|c|}
\hline \multirow{2}{*}{$\begin{array}{l}\text { Order, } \\
\tau\end{array}$} & \multirow{2}{*}{$\begin{array}{l}\text { Atuocorrelation } \\
\text { Coefficient }\end{array}$} & \multicolumn{2}{|c|}{$\begin{array}{l}\text { Lo and Mackinlay } \\
\text { Variance ratio test } Z^{*}(q)\end{array}$} & \multicolumn{2}{|c|}{$\begin{array}{l}\text { Diebold } \\
\text { Q-stat., } Q^{*}(\tau)\end{array}$} \\
\hline & & Stat. & $P$-value & Stat. & $P$-value \\
\hline \multicolumn{6}{|c|}{ A. US Returns } \\
\hline 1 & .0756 & 1.798 & .072 & 3.236 & .072 \\
\hline 2 & -.0395 & 1.238 & .216 & 4.686 & .096 \\
\hline 3 & -.0275 & .824 & .410 & 5.337 & .149 \\
\hline 4 & -.0630 & .315 & .753 & 8.346 & .079 \\
\hline 5 & -.0526 & -.147 & .883 & 10.69 & .058 \\
\hline 6 & -.0077 & -.438 & .661 & 10.74 & .097 \\
\hline 7 & -.0303 & -.687 & .492 & 11.44 & .120 \\
\hline 8 & .0105 & -.829 & .407 & 11.55 & .172 \\
\hline 9 & .0320 & -.871 & .383 & 12.69 & .177 \\
\hline 10 & .0189 & -.871 & .384 & 12.97 & .225 \\
\hline 15 & -.0277 & -.783 & .433 & 15.98 & .383 \\
\hline \multicolumn{6}{|c|}{ B. GK Returns } \\
\hline 1 & .1533 & 3.073 & .002 & 9.447 & .002 \\
\hline 2 & -.0181 & 2.573 & .010 & 9.573 & .008 \\
\hline 3 & -.0869 & 1.805 & .071 & 13.44 & .004 \\
\hline 4 & -.0363 & 1.290 & .197 & 14.12 & .007 \\
\hline 5 & .0229 & 1.060 & .289 & 14.42 & .013 \\
\hline 6 & .0575 & 1.034 & .301 & 16.87 & .009 \\
\hline 7 & .0847 & 1.158 & .247 & 22.66 & .002 \\
\hline 8 & .0609 & 1.325 & .185 & 26.06 & .001 \\
\hline 9 & -.0645 & 1.356 & .175 & 29.20 & .001 \\
\hline 10 & -.0017 & 1.371 & .170 & 29.21 & .001 \\
\hline 15 & -.0181 & 1.549 & .120 & 32.72 & .005 \\
\hline
\end{tabular}

Note: This table reports the test results for the autocorrelation of returns for both U.S. and Greek markets. Both Lo and MacKinlay (1988) variance ratio test and Diebold's (1988) $Q$ statistics are reported. The test statistics are corrected for serial correlation and heteroskedasticity. Returns are measured at daily intervals.

almost unchanged. Thus, both index series are non-stationary. The Johansen $(1988,1991)$ trace and $\lambda_{\max }$ multivariate tests show that the two series are not cointegrated at a lag order of five. ${ }^{15}$ Thus, the two market index series do not possess a long-term equilibrium relation and

15. The lag order $\mathrm{k}$ was set equal to five in table 3 . Results are qualitatively the same for $k=10$. The critical values are obtained from Osterwald-Lenum (1992). 
TABLE 3. Unit root and Cointegration Tests

\begin{tabular}{|c|c|c|c|c|}
\hline \multicolumn{5}{|c|}{ A. ADF, Phillips-Perron unit root tests ${ }^{\mathrm{a}}$} \\
\hline & $\triangle U S$ & \multicolumn{2}{|l|}{$\triangle G K$} & $\begin{array}{l}\text { Critical Values } \\
\text { at the } 5 \% \text { Level }\end{array}$ \\
\hline $\mathrm{ADF}$ (no trend) & -1.482 & \multicolumn{2}{|l|}{-.142} & -2.86 \\
\hline ADF (with trend) & -1.189 & \multicolumn{2}{|l|}{-1.044} & -3.41 \\
\hline Phillips-Perron (no trend) & -1.383 & \multicolumn{2}{|l|}{-.237} & -2.86 \\
\hline Phillips-Perron (with trend) & -1.415 & \multicolumn{2}{|l|}{-1.108} & -3.41 \\
\hline \multicolumn{5}{|c|}{ B. Johansen Cointegration Tests ${ }^{\mathrm{b}}$} \\
\hline & Trace & $\begin{array}{l}\text { Critical values at } \\
\text { the } 5 \% \text { level }^{\mathrm{b}}\end{array}$ & $\lambda_{\max }$ & $\begin{array}{l}\text { Critical Values at } \\
\text { the } 5 \% \text { level }\end{array}$ \\
\hline \multirow[t]{2}{*}{ Cointegrating Rank } & 1.38 & 8.18 & 1.38 & 8.18 \\
\hline & 6.78 & 17.95 & 5.4 & 14.9 \\
\hline
\end{tabular}

Note: ${ }^{\text {aThe }} \mathrm{ADF}$ test statistics are computed with five lags. Five non-zero autocovariances in Newey-West (1987) correction are also used for the Phillips-Perron (1988) tests. Results are qualitatively the same for 10 lags. The critical values of the ADF and Phillips-Perron tests are reported in Fuller (1976, p. 373). ${ }^{\mathrm{b}}$ The lag length, $k$, in the VECM of the Johansen test is set equal to 5. Results are qualitatively the same for $k=10$. The critical values are obtained from Osterwald-Lenum (1992).

the two markets are not cointegrated. The sensitivity of the cointegration tests to the lag order was also examined. The results remain almost unchanged as the lag order is changed from one to ten. For instance, when the lag order is set equal to one, the trace values $\left(\lambda_{\text {trace }}\right)$ are equal to $1.42(r=1)$ and $7.18(r=0)$, and $\lambda_{\max }$ equal to 1.42 $(r=1)$ and $5.76(r=0)$, which are all below the critical values. Again, there is no evidence of cointegration between the two markets. Similar results were obtained when the lag order was increased up to ten. Thus, the test results do not appear to be sensitive to the lag order. Moreover, the Engle and Kozick (1993) test for the ARCH common volatility shows no common volatility factor for the two markets. This suggests that the U.S. and Greek stock markets do not share the same volatility process. The lack of cointegration suggests that if return spillovers exist, they are, at most, short-run in nature. Moreover, the absence of common volatility implies that the unexpected component of returns for each market is idiosyncratic. This means that if volatility spillovers indeed exist, they should be modeled as a pairwise phenomenon. 
Table 4 shows the results of estimation for the bivariate EGARCH model using domestic returns (measured in local currency). It is found that there is no spillover for the conditional mean and variance of returns. The coefficient $c$, which reflects the potential spillover in mean returns, is not significant for both markets. In contrast, the returns exhibit a significant first-order moving average in both markets, suggesting that returns are serially correlated. The $b$ coefficients are significant at the one-percent level. Both markets show a strong pattern of ARCH and GARCH effects. The coefficients of $\alpha$ and $\beta$ are significant at the one-percent level. The volatility depends on its own past innovation. The persistence of volatility is measured by $\beta$. The values of $\beta$ are all significantly less than one, a condition necessary for the unconditional variance to be finite. The higher $\beta$ value for U.S returns suggests that volatility persistence is stronger for the U.S. market. The asymmetric volatility parameter $(O)$ is significantly negative for the U.S. market, but it is not significant for the Greek market. This suggests that in the U.S. market the arrival of bad news increases the volatility of the market, whereas it has no effect on the volatility of the Greek market. Finally, the volatility spillover parameter $\gamma$ is very close to zero and statistically insignificant for both markets, indicating that there is no spillover in volatility.

The value of the correlation coefficient $\rho$ in the variance-covariance matrix is very close to zero, .016. The degree of freedom of the $t$ distribution $v$ is 6.49. The results of the diagnostic check on the behavior of standardized residuals $z_{i . t}$, the squared $z_{i, t}^{2}$, and the cross products $z_{t, i} z_{j, t}$ show little evidence of misspecification. The Ljung-Box (1978) Q(12) statistics show no sign of autocorrelation for these three variables. Also, the insignificance of Engle and Ng's (1993) asymmetric diagnostic tests, including sign bias, negative bias, positive bias, and joint tests, indicate that the EGARCH model is reasonably specified. The asymmetric tests are reported because Engle and $\mathrm{Ng}$ (1993) indicate that the Ljung-Box may lack power in detecting misspecifications related to the asymmetric effects. Both tests indicate that the estimated model fits the data rather well.

The EGARCH model is also estimated using U.S. dollar returns. These results are reported in table 5 and are quite similar to those in table 4 for domestic returns. Again, the results show a strong negative asymmetric volatility effect in the U.S. market, whereas there is no such asymmetry in the Greek market. Both markets exhibit a strong pattern of clustering and time-variations in volatility that are well captured by 
TABLE 4. Mean and Volatility Spillovers: Bivariate EGARCH Model: Local Currency Returns

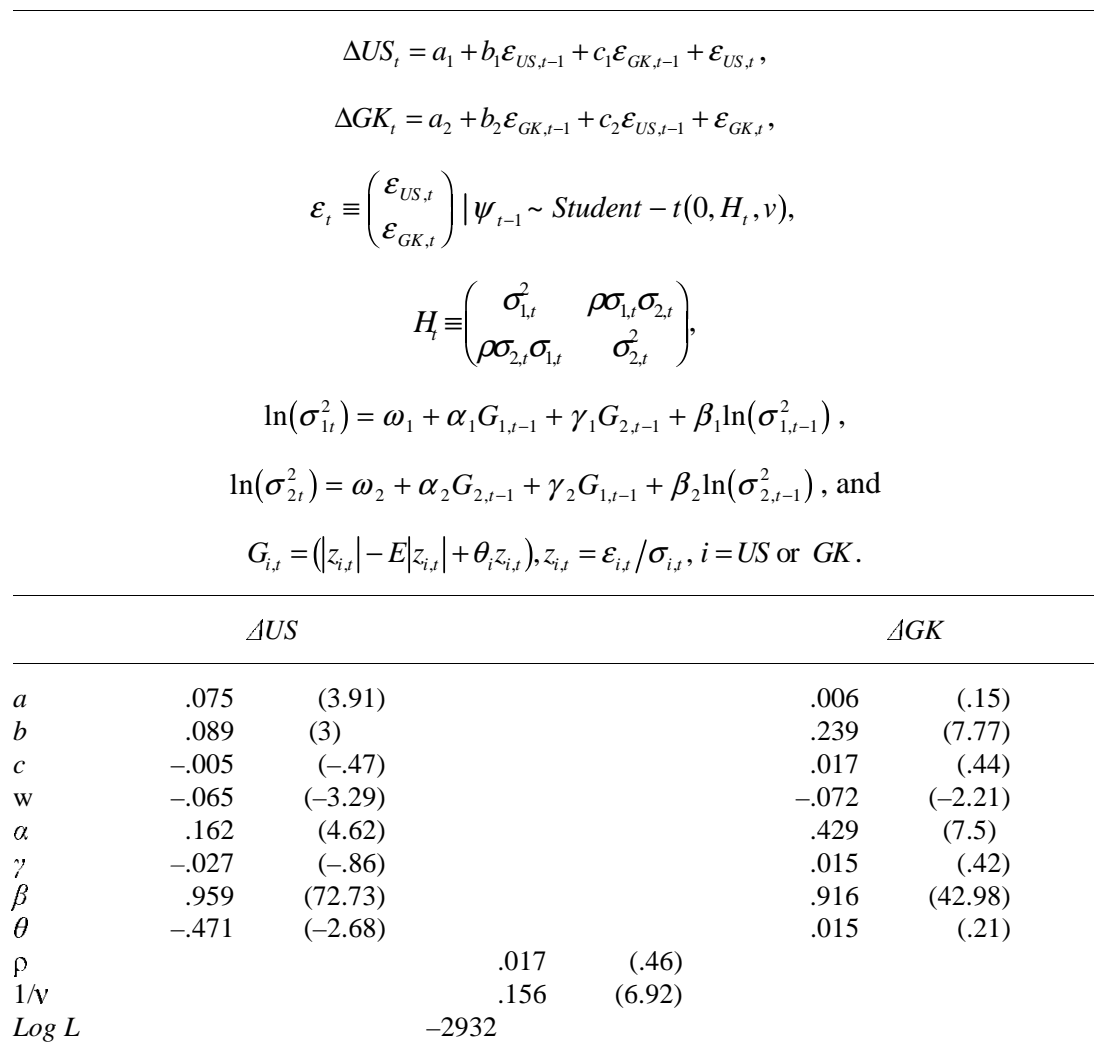

Diagnostic checking: $P$-values of test statistics

\begin{tabular}{lll}
\hline & $A U S$ & \multicolumn{1}{c}{$\Delta K K$} \\
\hline Ljung-Box $Q(12)$-Statistics & & \\
$z_{i t}$ & .713 & .237 \\
$z_{i t}{ }^{2}$ & .904 & .953 \\
$z_{E Y,} z_{E D, t}$ & \\
Engle and Ng's Asymmetric Tests & .844 & .048 \\
Sign Bias Test & .684 & .759 \\
Negative Size Bias Test & .119 & .414 \\
Positive Size Bias Test & .142 & .167 \\
Joint Test & .165 & \\
\hline
\end{tabular}

Note: The EGARCH model allows for both mean and volatility spillovers and incorporates the effect of the first-order moving average. $H$ is the conditional variance-covariance matrix. $\gamma_{1}$ and $\gamma_{2}$ measure the volatility spillover effect, and $O$ measures the asymmetric effect of news. Engle and Ng's (1993) asymmetric diagnostic tests are conducted to check whether the EGARCH model is properly specified. Returns are measured in units of U.S. dollars. $t$-statistics are in parentheses. 
TABLE 5. Mean and Volatility Spillovers: Bivariate EGARCH Model: U.S. Dollar Returns

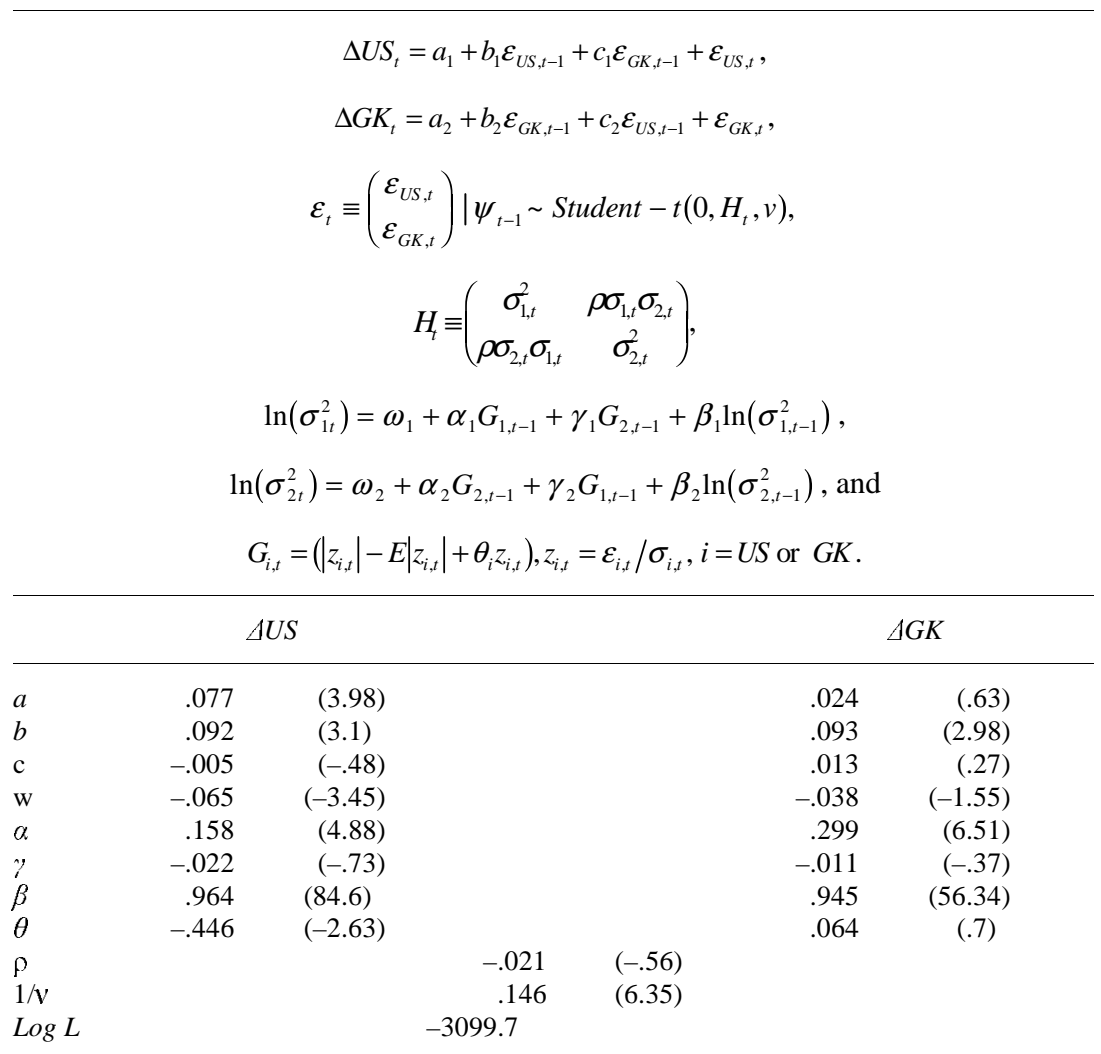

Diagnostic checking: $P$-values of test statistics

\begin{tabular}{lll}
\hline & \multicolumn{1}{c}{$A U S$} & \multicolumn{1}{c}{$\Delta K$} \\
\hline Ljung-Box $Q(12)$-Statistics & & \\
$z_{i t}$ & .905 & .542 \\
$z_{i t}{ }^{2}$ & .905 & .785 \\
$z_{E Y, t} z_{E D, t}$ & .844 & \\
Engle and Ng's Asymmetric Tests & & \\
Sign Bias Test & .733 & .241 \\
Negative Size Bias Test & .086 & .7 \\
Positive Size Bias Test & .122 & .198 \\
Joint Test & .095 & .558 \\
\hline
\end{tabular}

Note: The EGARCH model allows for both mean and volatility spillovers and incorporates the effect of the first-order moving average. $H$ is the conditional variance-covariance matrix. $\gamma_{1}$ and $\gamma_{2}$ measure the volatility spillover effect, and $O$ measures the asymmetric effect of news. Engle and Ng's (1993) asymmetric diagnostic tests are conducted to check whether the EGARCH model is properly specified. Returns are measured in units of U.S. dollars. $t$-statistics are in parentheses. 
the EGARCH model. However, there is still no sign of a significant spillover in volatility between the two markets.

\section{Conclusion}

This article examines the international transmission of information between a large, well-developed market and a small, emerging market using an extended bivariate EGARCH model. It is found that the EGARCH model with autoregressive terms explains the daily stock returns very well. Both the U.S. and Greek stock market returns exhibit a significant first-order moving average. The return distribution of the Greek market has a much higher volatility and fatter tail than that of the U.S. market. This higher volatility in the Greek market is compensated to some extent by higher returns. Return volatilities of both markets exhibit strong persistence over time.

The results show no spillovers between these two markets for the conditional mean and variance. Results in general support the "heat wave" hypothesis for these two markets. Also, the cointegration test shows that these two markets are not integrated. Contrary to previous studies of the world's large financial markets, the evidence here supports the contention that international markets, especially for an emerging economy, remain segregated. The results show that the U.S. and Greek stock markets are not related to each other either in the short run or in the long run. This lack of a strong relationship may be due to differences in economic, social, and political structures. These results are intriguing because they are contrary to previous findings that the U.S. market often has a powerful influence on foreign markets.

The results of this article, along with previous findings, cast doubt on the argument that international markets are increasingly related. As noted above, Booth, Martikainen, and Tse (1997) found that the four Scandinavian stock markets are only weakly related to each other despite strong regional economic cooperation, trade relations, and closely related economic and financial systems among these nations. Harvey (1995) reports that, compared to developed markets, the correlation between most emerging markets and other markets has been quite low. His results include three European countries: Greece, Portugal, and Turkey. Bekaert and Harvey (1995) also find that, despite the recent trend toward abolition of investment restrictions and the substantial inflows of foreign capital, some emerging equity markets 
have actually become more segmented from world capital markets. This article provides further evidence that the Greek market is not correlated with major world capital markets such as New York. However, a beneficial implication of this is that the low correlation may provide a possible opportunity for portfolio diversification.

\section{References}

Bae, K. H., and Karolyi, G. A. 1994. Good news, bad news and international spillovers of stock return volatility between Japan and the U.S. PacificBasin Finance Journal 2: 405-438.

Bekaert, G., and Harvey, C. R. 1995. Time-varying world market integration. Journal of Finance 50: 403-444.

Bollerslev, T. 1986. Generalized autoregressive conditional heteroskedasticity. Journal of Econometrics 31: 307-327.

Bollerslev, T. 1987. A conditional heteroskedastic time series model for speculative prices and rates of return. Review of Economics and Statistics 69: 542-547.

Bollerslev, T. 1990. Modelling the coherence in short-run nominal exchange rates: A multivariate generalized ARCH model, Review of Economics and Statistics 72: 498-505.

Booth, G. G.; Martikainen, T.; and Tse, Y. 1997. Price and volatility spillovers in Scandinavian stock markets. Journal of Banking and Finance 21: 811823.

Dickey, D., and Fuller, W. A. 1979. Distribution of the estimates for autoregressive time series with a unit root. Journal of the American Statistical Association 74: 427-431.

Dickey, D., and Fuller, W. A. 1981. Likelihood ratio statistics for autoregressive time series with a unit root. Econometrica 49: 1057-1072.

Diebold, F. X., 1988. Empirical Modeling of Exchange Rate Dynamics. New York: Springer-Verlag.

Domowitz, I.; Glen, J.; and Madhavan, A. 1998. International cross-listing and order flow migration: Evidence from an emerging market. Journal of Finance 53: 2001-2027.

Engle, R. F., and Kozicki, S. 1993. Testing for common features. Journal of Business and Economic Statistics 11: 369-380.

Engle, R. F., and Ng, V. K. 1993. Measuring and testing the impact of news on volatility. Journal of Finance: 1749-1778.

Fuller, W. 1976. Introduction to Statistical Time Series. New York: Wiley.

Hamao, Y.; Masulis, R. W.; and Ng, V. K. 1990. Correlation in price changes and volatility across international stock markets. Review of Financial Studies 3: 281-307. 
Harvey, C. R. 1995. Predictable risk and return in emerging markets. Review of Financial Studies 8: 773-816.

Johansen, S. 1988. Statistical analysis of cointegration vectors. Journal of Economic Dynamics and Control 12: 231-254.

Johansen, S. 1991. Estimation and hypothesis testing of cointegrating vectors in Gaussian vector autoregressive models. Econometrica 59: 1551-1580.

Kahya, E. 1997. Correlation of Returns in Non-Contemporaneous Markets. Multinational Finance Journal 1: 123-135.

Koutmos, G., and Booth, G. G. 1995. Asymmetric volatility transmission in international stock markets. Journal of International Money and Finance 14: 747-762.

Lin, W.; Engle, R. F.; and Ito, T. 1994. Do bulls and bears move across borders? International transmission of stock returns and volatility. Review of Financial Studies 7: 507-538.

Ljung, G., and Box, G. 1978. On a measure of lack of fit in time series models. Biometrica 65: 297-303.

Lo, A. W., and MacKinlay, A. C. 1988. Stock market prices do not follow random walks: Evidence from a simple specification test. Review of Financial Studies 1: 41-66.

Miller, M. H.; Muthuswamy, J.; and Whaley, R. E. 1994. Mean reversion of Standard \& Poor's 500 Index basis changes: Arbitrage-induced or statistical illusion? Journal of Finance 49: 479-513.

Nelson, D. 1991. Conditional heteroskedasticity in asset returns: A new approach. Econometrica 59: 347-370.

Newey, W. K., and West, K. D. 1987. A simple positive semi-definite, heteroskedasticity and autocorrelation consistent covariance matrix. Econometrica 55: 703-708.

Niarchos, N. A., and Georgakopoulos, M. C. 1986. The effect of annual corporate profit reports on the Athens Stock Exchange: An empirical investigation. Management International Review 26: 64-72.

Osterwald-Lenum, M. 1992. A note with quantiles of the asymptotic distribution of the maximum likelihood cointegration rank test statistics. Oxford Bulletin of Economics and Statistics 54: 461-471.

Papaioannou, G. J., and Philippatos, G. C. 1982. The intervaling effect under non-synchronous trading and price adjustment lags in the Athens Stock Exchange. Spoudai 4: 627-639.

Phillips, P., and Perron, P. 1988. Testing for a unit root in time series regression. Biometrica 75: 335-346.

Susmel, R., and Engle, R. F. 1994. Hourly volatility spillovers between international equity markets. Journal of International Money and Finance 13: 3-25.

Theodossiou, P.; Koutmos, G.; and Negakis, C. 1993. The international relation between the U.S. and Greek Stock Markets: A conditional variance tale analysis. The International Journal of Finance 5: 492-508. 
Tse, Y. 1998. International transmission of information: Evidence from the Euroyen and Eurodollar futures markets. Journal of International Money and Finance 17: 909-929.

Wu, C., and Su, Y. 1998. Dynamic relations among international stock markets. International Review of Economics and Finance 7: 63-84 